\title{
Carne de avestruz: rendimento de carcaça e aspectos físicos e químicos
}

\author{
Ostrich meat: carcass yield and physical and chemical characteristics
}

\author{
Augusto BALOG ${ }^{1 *}$, Ariel Antônio MENDES ${ }^{1}$, Ibiara Correia de Lima ALMEIDA PAZ \\ Marleide da Costa SILVA ${ }^{1}$, Sabrina Endo TAKAHASHI ${ }^{1}$, Claudia Marie KOMIYAMA ${ }^{1}$
}

\section{Resumo}

O objetivo deste estudo foi avaliar o rendimento de carcaça e os aspectos físicos e químicos da carne de avestruzes abatidos comercialmente no Brasil. E para isso acompanhou-se o processo de abate e desossa de um abatedouro comercial de avestruzes. Utilizou-se 12 machos e 12 fêmeas, com idade entre 13 e 15 meses, da subespécie African Black. No momento da desossa foram avaliados: o pH, a temperatura e a coloração dos músculos. A composição química e mineral foi determinada segundo metodologias propostas pela AOAC. O pH apresenta diferença significativa em relação aos diferentes músculos. Ao avaliar a coloração dos músculos em relação ao sexo, observou-se que a luminosidade foi maior para os machos, contribuindo significativamente para que a carne fosse mais brilhante que a das fêmeas. Houve diferença significativa em relação ao sexo sobre os teores de proteína bruta e lipídios. O teor de minerais não apresentou diferença significativa em relação ao sexo. Porém, observa-se diferença significativa entre os diferentes músculos avaliados. Conclui-se então que, a rentabilidade das carcaças de avestruzes tem sido comparável à média mundial, demonstrando o empenho entre os criadores em produzir carne de avestruz de maneira competitiva, além da mesma apresentar características organolépticas e nutricionais que agradam ao consumidor.

Palavras-chave: cor; estrutiocultura; nutrientes; $p H$.

\begin{abstract}
This study aimed at evaluating carcass yield and qualitative meat traits of commercially slaughtered ostriches in Brazil. A total number of 12 males and 12 females, between 13 and 15 months of age, of the subspecies African Black, was used. Carcass pH, temperature, and color were evaluated at deboning. Chemical and mineral compositions were analyzed according to the methods proposed by the AOAC. Differences in $\mathrm{pH}$ were found among muscles. When color was evaluated, it was observed that luminosity was higher for males, showing that their meat was significantly shinier than that of females. Muscles of females presented higher lipid and crude protein content, as compared to males. Mineral content was not significantly different for female and male meat, however, there was a difference among different muscles. It was concluded that carcass yield was comparable to the world average, demonstrating the effort of ostrich producers to produce competitive ostrich meat, with sensory and nutritional characteristics that please consumers.
\end{abstract}

Keywords: color; nutrients; ostrich breeding; $\mathrm{pH}$.

\section{Introdução}

Nos dias atuais é cada vez maior a preocupação com uma alimentação saudável. Diante disso, o consumo de carnes alternativas que apresentem baixos índices de gordura e, ao mesmo tempo, sejam nutritivas e saborosas, tem sido bastante estimulado por médicos e profissionais da área de saúde. Nesse aspecto, a carne de avestruz surge como uma opção que atende perfeitamente a essas necessidades (HOFFMAN; MELLET, 2003) e, como já acontece na África do Sul, Espanha, China, Israel e em muitos países da Europa, ela já está conquistando o paladar dos brasileiros, estes culturalmente apreciadores de carne bovina.

O nome científico do avestruz é Struthio camelus. Pertencem ao grupo das ratitas, ou seja, aves que não voam. O avestruz começou a ser criado comercialmente na África do Sul, na metade do século passado, principalmente para exploração de plumas, que com o advento da I e II Guerras Mundiais e a quebra da
Bolsa de Valores, perdeu seu valor econômico, porém na década de 60 outros produtos desse animal, principalmente a carne e a pele, começaram a despertar interesse dado à alta qualidade de ambas (HOFFMAN; MELLET, 2003).

As subespécies utilizadas na estrutiocultura comercial são African Black, Blue Neck e Red Neck. O African Black foi formado a partir de 3 subespécies (australis, camelus e syriacus), com o objetivo de se obter um animal de porte menor, mas que produzisse uma grande quantidade de plumas de boa qualidade, tivesse uma grande área de pele e fosse dócil. São os mais encontrados nos criadouros de todo o mundo (CARRER; KORNFELD, 1999).

No Brasil, o mercado de carne de avestruz vem crescendo devido à iniciativa de um número cada vez maior de produtores que têm direcionado suas criações para venda de animais para

Recebido para publicação em 7/2/2007

Aceito para publicação em 10/7/2007 (002278)

${ }^{1}$ Departamento de Produção Animal, Faculdade de Medicina Veterinária e Zootecnia, Universidade Estadual Paulista - UNESP, CP 560, CEP 18618-000, Botucatu - SP, Brasil, E-mail: gutobalog@fmvz.unesp.br

${ }^{*}$ A quem a correspondência deve ser enviada 
abate, aliado à crescente preocupação da população brasileira em relação a uma alimentação saudável. Nos últimos tempos, a carne de avestruz tem consolidado um nicho no mercado de carnes brasileiro, a exemplo do que já ocorre a alguns anos em todo o mundo. Com isso, inúmeros abatedouros têm distribuído seus produtos em diversos restaurantes e supermercados. Alguns iniciando processos de exportação (ACAB, 2006).

Os avestruzes são abatidos aproximadamente aos 14 meses, idade em que ele apresenta as melhores condições zootécnicas para oferecer uma melhor qualidade de couro e carne (SWART, 1981).

$\mathrm{O}$ avestruz possui um rendimento de carcaça em torno de 30 a 35\%, porém, respeitando técnicas de processamento e biossanitárias adequadas ao avestruz, consegue-se aumentar este índice para 35 a 42\%, ou seja, uma melhora de performance de 20\% na rentabilização dos produtos cárneos (MUNIZ, 2004).

Devido ao fato do avestruz ser uma ave corredora, ele não possui o músculo peitoral desenvolvido e as asas são atrofiadas. Logo, a parte mais apreciada por possuir uma maior quantidade de carne são as pernas. Mas outras partes da ave também são aproveitadas, mesmo em pedaços menores.

A caracterização do rendimento de carcaça é muito importante por fornecer subsídios para um melhor aproveitamento tecnológico da espécie e de seus subprodutos. De modo geral, no que diz respeito à relação carne $\mathbf{X}$ ossos $\mathbf{X}$ gordura, a composição da carcaça depende de características genéticas, da idade, da subespécie, da alimentação e do manejo, bem como das condições ambientais (PARDI, 2001).

Sales e Mellet (1995) observaram que o declínio do $\mathrm{pH}$ post-mortem pode variar entre os diferentes músculos. Enquanto músculos como o Gastrocnemius pars interna, Femorotibialis, Iliotibialis lateralis e Iliofemoralis apresentam declínio normal, o músculo Ambiens e o Iliofibularis apresentam declínio mais acelerado nas primeiras 2 horas post-mortem, e depois ocorre um ligeiro aumento desse $\mathrm{pH}$.

A cor das carnes é um importante atributo de qualidade, pois é um dos primeiros aspectos a serem avaliados pelos consumidores nas gôndolas dos supermercados. A sua avaliação é um indício do seu frescor e influencia diretamente o consumidor na decisão final de sua aquisição (FLETCHER; QIAO; SMITH, 2000). Embora seja carne de ave, sua cor é fortemente avermelhada, podendo assumir colorações mais arroxeadas, dependendo da alimentação e do procedimento de abate. $\mathrm{O}$ fato da carne de avestruz possuir uma tonalidade vermelha mais acentuada se deve ao fato da mesma possuir um teor elevado de ferro em sua composição, mais até que a carne bovina (MUNIZ, 2004).

O maior atrativo da carne de avestruz está em seu baixo teor de gordura em comparação às outras carnes, com a vantagem de possuir um alto teor de ferro, diferente das carnes de outras aves que apresentam pouco ferro em sua composição, se encaixando perfeitamente no cardápio de dietas para anêmicos ou mesmo de emagrecimento. Além disso, os avestruzes não necessitam do uso de hormônios e aditivos devido a sua precocidade natural, o que torna a carne mais saudável e segura em relação a resíduos.

Na verdade, a característica de carne magra se deve à distribuição da gordura no corpo do avestruz, que se concentra em volta do estômago e abaixo da pele, possibilitando a separação desse volume. A carne de avestruz é extremamente magra, possuindo baixo conteúdo de gordura ( $2,8 \%$ em média), sendo que a maior parte desta, aproximadamente $2 / 3$ do total, é de gordura insaturada de fácil digestão (SALES, 1996).

A carne de avestruz, além de possuir baixos índices de gordura, é rica em proteínas e minerais, e tem sido bastante estimulada por profissionais da área de saúde por proporcionar uma alternativa de dieta balanceada.

Existem variações no valor nutricional das carnes em relação aos cortes cárneos, idade, alimentação, sexo e raça do animal, embora não sejam significativas.

Diante desses aspectos e da demanda por parte dos consumidores que têm requerido maiores informações quanto à qualidade deste produto, o objetivo desse estudo foi avaliar o rendimento de carcaça e os aspectos físicos e químicos da carne de avestruzes abatidos comercialmente no Brasil.

\section{Material e métodos}

Utilizou-se neste experimento 24 animais, sendo 12 machos e 12 fêmeas, com idade entre 13 e 15 meses, da subespécie African Black, provenientes de um único criatório, onde foram criados sob as mesmas condições nutricionais e sanitárias. $\mathrm{O}$ abate ocorreu em um abatedouro comercial exclusivo para avestruzes na cidade de Araçatuba-SP.

Os animais foram pesados na propriedade para posteriormente serem avaliadas as perdas de peso no transporte e durante o período de descanso e dieta hídrica, que foi de 24 horas.

As aves foram pesadas a fim de se obter seu peso vivo, no momento que entravam na área de sangria. $\mathrm{O}$ abatedouro seguiu os procedimentos de abate humanitário descrito por Lima (2005). As aves foram encapuzadas, sendo aturdidas por eletronarcose, utilizando-se pinças elétricas, com corrente de 1,1 a 1,3 A, sob tensão de 80 a 90 volts, durante 3 a 5 segundos, semelhantemente ao aturdimento dos suínos. Em seguida, os animais foram suspensos por suas pernas, sendo submetidos à sangria por drenagem carotídeo/jugular durante um tempo de 8 a 10 minutos.

Estando o animal suspenso pelas pernas, foi efetuada a abertura da caixa torácica com uma serra mecânica, no sentido torácico/abdominal. Após a evisceração, foi realizada limpeza da carcaça com água a $80^{\circ} \mathrm{C}$ para eliminação de todos os restos de sangue, sacos aéreos e restos de vísceras, que possam comprometer a qualidade microbiológica da carne. Estes procedimentos duraram em média 30 minutos.

As carcaças quentes foram pesadas antes de entrar na câmara fria, onde ficaram sob resfriamento durante 24 horas a $4{ }^{\circ} \mathrm{C}$. Após o resfriamento, a desossa foi realizada manualmente em sala climatizada a $10^{\circ} \mathrm{C}$, onde foram separados os 11 músculos que são comercializados individualmente, além de outros 3 que 
são comercializados em conjunto, por serem muito pequenos, ou então na forma de carne picada. Além dos subprodutos como pescoço, asas, fígado e coração. Todos os cortes foram identificados e pesados em balança de precisão.

O rendimento de carcaça foi calculado a partir do peso da carcaça quente dos animais, dividindo-se o peso da carcaça X 100 pelo peso vivo. $\mathrm{O}$ rendimento dos cortes em relação à carcaça quente foi obtido dividindo-se o peso do corte $X 100$ pelo peso da carcaça quente.

Após a desossa foram mensurados o $\mathrm{pH}$ e a temperatura, com o uso de eletrodo de penetração, utilizando um pHmetro (Sentron, modelo 1001) acoplado a uma sonda (Sentron tipo LanceFET, modelo 1074001); a coloração foi determinada através de um espectrofotômetro do tipo Hunter, no sistema CIELab*, onde foram avaliados os parâmetros ${ }^{\star} \mathrm{L}$ (luminosidade), ${ }^{\star} \mathrm{a}$ (teor de vermelho) $\mathrm{e}^{\star} \mathrm{b}$ (teor de amarelo). Após esse procedimento foram coletadas amostras dos seguintes músculos: Gastrocnemius internus, Gastrocnemius externus, Femorotibialis complex, Iliotibialis lateralis, Iliofibularis e Obturatorius medialis para a avaliação da composição química e mineral.

A avaliação da composição química da carne de avestruz, a fim de determinar suas qualidades nutricionais, foi realizada no Laboratório de Bromatologia da FMVZ/UNESP - campus de Botucatu-SP. A umidade foi determinada seguindo o método gravimétrico da AOAC (1997), a proteína bruta pelo método de Kjeldahl-Micro (AOAC, 1997) para determinação do nitrogênio total. A proteína bruta foi calculada em função dos teores de nitrogênio total, multiplicado pelo fator 6,25 . O teor de lipídios foi determinado pelo método de Soxlet descrito pela AOAC (1997) e o resíduo mineral fixo foi realizado segundo o método gravimétrico recomendado pela AOAC (1997).

A avaliação da composição mineral da carne foi realizada no Laboratório de Análise Química da FCA/UNESP - campus de Botucatu-SP. Foram quantificados os teores de fósforo (P), potássio $(\mathrm{K})$, cálcio $(\mathrm{Ca})$, magnésio $(\mathrm{Mg})$, cobre $(\mathrm{Cu})$, ferro $(\mathrm{Fe})$, manganês $(\mathrm{Mn})$ e zinco $(\mathrm{Zn})$. A composição mineral de cada amostra foi obtida através de digestão nitricoperclórica. O P foi determinado por calorimetria, o K por fotometria de chama e os demais elementos por espectrofotometria de absorção atômica, conforme descrito por Malavolta, Vitti e Oliveira (1997).

A análise estatística dos dados foi feita pelo método de análise de variância (ANOVA), com o auxílio do procedimento GLM (General Linear Models) do programa SAS (1999). Para verificar diferenças significativas entre as médias dos tratamentos foi utilizado o teste de Tukey a $5 \%$ de probabilidade.

\section{Resultados e discussão}

Atendendo a normas internacionais de abate humanitário, visando o bem-estar e uma melhor qualidade da carne, as aves foram transportadas durante a noite e em caminhões adaptados e permaneceram em descanso por 24 horas antes do sacrifício, que ocorreu sob condições mínimas de estresse. Porém, foram observadas perdas durante o transporte e o jejum que são apresentadas na Tabela 1 .
A privação de alimento e água conduz à perda de peso do animal. A razão da perda de peso relatada na literatura científica é extremamente variável, de 0,75 a 11\% do peso vivo nas primeiras 24 horas de privação de água e alimento (KNOWLES, 1999; WARRIS, 1990). A perda de peso dos animais tem razão direta com a espécie, o tempo de transporte, as condições do curral de espera, o nível de estresse e as condições climáticas. A perda de peso é motivada inicialmente pela perda do conteúdo gastrintestinal e o acesso à água durante a privação de alimento reduz as perdas. Bovinos perdem em média $6 \%$ do seu peso corporal entre a saída da fazenda e a entrada na área de insensibilização, enquanto que suínos perdem cerca de $1 \%$ apenas.

O rendimento de carcaça, os cortes comerciais e os subprodutos são apresentados nas Tabelas 2, 3 e 4.

Lima (2005) afirma que avestruzes, abatidos experimentalmente no Estado de São Paulo, com idade entre 13 e 14 meses pesam entre 111 e $120 \mathrm{~kg}$ e apresentam um rendimento de carcaça de cerca de 60,6\%. Os dados obtidos com esse estudo são contraditórios em relação a este autor, já que o peso vivo de $88,921 \mathrm{~kg}$ e o rendimento de carcaça de $51,86 \%$ estão mais próximos do que foi relatado por Pollok (1997), que observou que o peso vivo médio dos animais que eram abatidos comer-

Tabela 1. Perdas de peso durante o transporte e o jejum de avestruzes.

\begin{tabular}{ccl}
\hline Sexo & Perdas no jejum & $\mathrm{CV}^{*}$ \\
\hline Macho & $5,59 \pm 2,56$ & 45,82 \\
Fêmea & $5,83 \pm 1,28$ & 21,97 \\
Média & $5,71 \pm 1,94$ & 35,473 \\
\hline
\end{tabular}

${ }^{*}$ Coeficiente de variação.

Tabela 2. Rendimento de carcaça e músculos desossados por região anatômica de avestruzes aos 14 meses de idade.

\begin{tabular}{|c|c|c|c|c|}
\hline & Sexo & & Carcaça (\%) & $\mathrm{CV}^{\star}$ \\
\hline \multirow[t]{3}{*}{ Peso vivo (kg) } & Macho & $89,294 \pm 4,271$ & - & 4,78 \\
\hline & Fêmea & $88,175 \pm 2,925$ & - & 3,32 \\
\hline & Média & $88,921 \pm 3,845$ & - & 4,32 \\
\hline \multirow[t]{3}{*}{ Peso de carcaça (kg) } & Macho & $45,831 \pm 2,488$ & - & 5,43 \\
\hline & Fêmea & $46,462 \pm 2,876$ & - & 6,19 \\
\hline & Média & $46,042 \pm 2,578$ & - & 5,60 \\
\hline \multirow{3}{*}{$\begin{array}{l}\text { Rendimento de } \\
\text { carcaça (\%) }\end{array}$} & Macho & $51,42 \pm 3,53$ & 100 & 6,87 \\
\hline & Fêmea & $52,75 \pm 3,78$ & 100 & 7,17 \\
\hline & Média & $51,86 \pm 3,59$ & 100 & 6,92 \\
\hline \multirow{3}{*}{$\begin{array}{l}\text { Músculos da coxa } \\
\text { desossada (\%) }\end{array}$} & Macho & $7,374 \pm 0,27$ & 14,13 & 5,08 \\
\hline & Fêmea & $7,304 \pm 0,22$ & 14,67 & 5,21 \\
\hline & Média & $7,340 \pm 0,50$ & 14,40 & 5,13 \\
\hline \multirow{3}{*}{$\begin{array}{l}\text { Músculos da } \\
\text { sobrecoxa } \\
\text { desossada (\%) }\end{array}$} & Macho & $4,765 \pm 0,07$ & 9,15 & 4,79 \\
\hline & Fêmea & $4,604 \pm 0,05$ & 9,25 & 7,40 \\
\hline & Média & $4,684 \pm 0,11$ & 9,20 & 6,18 \\
\hline \multirow{3}{*}{$\begin{array}{l}\text { Músculos do dorso } \\
\text { desossado (\%) }\end{array}$} & Macho & $6,480 \pm 0,04$ & 12,43 & 6,86 \\
\hline & Fêmea & $6,357 \pm 0,05$ & 12,78 & 8,31 \\
\hline & Média & $6,418 \pm 0,08$ & 12,61 & 7,58 \\
\hline
\end{tabular}

Médias seguidas de mesma letra maiúscula na linha e médias seguidas de mesma letra minúscula na coluna não diferem entre si pelo Teste de Tukey $(p>0,05) e^{*}$ coeficiente de variação. 
Balog et al.

Tabela 3. Rendimento de cortes comerciais da carcaça desossada de avestruzes aos 14 meses de idade.

\begin{tabular}{|c|c|c|c|c|}
\hline & Músculo & Nome comum & Sexo & Carcaça (\%) \\
\hline \multirow[t]{12}{*}{$\mathrm{Coxa} \mathrm{CV}^{*} 15,38$} & Tibiotarsianus complex (\%) & Músculo & Macho & $4,12 \pm 0,40$ \\
\hline & & & Fêmea & $4,15 \pm 0,31$ \\
\hline & & & Média & $4,13 \pm 0,34$ \\
\hline & M. Fibularis longus (\%) & Coxa média & Macho & $2,08 \pm 0,20$ \\
\hline & & & Fêmea & $3,02 \pm 0,81$ \\
\hline & & & Média & $2,55 \pm 0,74$ \\
\hline & M. Gastrocnemius internus (\%) & Coxa interna & Macho & $3,79 \pm 0,42$ \\
\hline & & & Fêmea & $3,57 \pm 0,83$ \\
\hline & & & Média & $3,68 \pm 0,63$ \\
\hline & M. Gastrocnemius externus (\%) & Coxa externa & Macho & $4,14 \pm 0,35$ \\
\hline & & & Fêmea & $3,92 \pm 0,17$ \\
\hline & & & Média & $4,03 \pm 0,28$ \\
\hline \multirow[t]{9}{*}{ Sobrecoxa $\mathrm{CV}^{\star} 18,84$} & M. Femurotibialis complex (\%) & Apex & Macho & $3,19 \pm 0,51$ \\
\hline & & & Fêmea & $2,98 \pm 0,37$ \\
\hline & & & Média & $3,08 \pm 0,43$ \\
\hline & M. Iliotibialis lateralis (\%) & Redondo & Macho & $4,47 \pm 0,37$ \\
\hline & & & Fêmea & $4,48 \pm 0,77$ \\
\hline & & & Média & $4,47 \pm 0,57$ \\
\hline & M. Flexor cruris lateralis (\%) & Faixa externa & Macho & $1,49 \pm 0,10$ \\
\hline & & & Fêmea & $1,80 \pm 069$ \\
\hline & & & Média & $1,65 \pm 0,49$ \\
\hline \multirow[t]{12}{*}{ Dorso $\mathrm{CV}^{\star} 16,72$} & M. Iliofibularis (\%) & Leque & Macho & $6,39 \pm 0,66$ \\
\hline & & & Fêmea & $5,98 \pm 0,30$ \\
\hline & & & Média & $6,19 \pm 0,53$ \\
\hline & M. Obturatorius medialis (\%) & Filé mignon & Macho & $1,49 \pm 0,17$ \\
\hline & & & Fêmea & $1,77 \pm 0,15$ \\
\hline & & & Média & $1,63 \pm 0,21$ \\
\hline & M. Iliofemuralis internus (\%) & Faixa interna & Macho & $2,37 \pm 0,34$ \\
\hline & & & Fêmea & $2,42 \pm 0,65$ \\
\hline & & & Média & $2,40 \pm 0,49$ \\
\hline & M. Iliotibialis cranialis (\%) & Plano & Macho & $2,18 \pm 0,32$ \\
\hline & & & Fêmea & $2,60 \pm 0,75$ \\
\hline & & & Média & $2,39 \pm 0,59$ \\
\hline
\end{tabular}

Médias seguidas de mesma letra maiúscula na linha e médias seguidas de mesma letra minúscula na coluna não diferem entre si pelo Teste de Tukey ( $\mathrm{p}>0,05)$; $\mathrm{e}^{*}$ coeficiente de variação.

cialmente nos Estados Unidos é de $99,7 \mathrm{~kg}$, enquanto que o rendimento de carcaça é de $49,6 \%$. Com relação ao rendimento dos principais músculos de interesse comercial, observou-se uma estreita relação entre o rendimento dos mesmos observados neste estudo e os dados relatados por Segóvia e Muniz (2004). Não foi observada diferença significativa $(\mathrm{p}>0,05)$ em relação ao sexo dos animais, concordando com o que foi observado por Horbañczuk et al. (1998).

Com relação aos aspectos físicos, foi possível observar com esse estudo que a carne de avestruz caracteriza-se por um alto $\mathrm{pH}$ final, medido após 24 horas post-mortem. Os valores médios de $\mathrm{pH}$ final observados nas carnes de avestruzes permitem classificá-los como um tipo de carne intermediária entre normal $(\mathrm{pH}<5,8)$ e alto $(\mathrm{pH}>6,2)$. Valores de $\mathrm{pH}$ superiores a 6,2 conduziriam a uma carne mais escura e diminuiriam sua qualidade tanto física quanto microbiológica. Os aspectos físicos, a temperatura, o pH e a coloração dos músculos, observados neste estudo, estão apresentados nas Tabelas 5 e 6.
$\mathrm{O}$ pH não apresentou diferença significativa $(\mathrm{p}>0,05) \mathrm{em}$ relação às regiões avaliadas e em relação ao sexo. Estes resultados obtidos estão de acordo com o que foi descrito por Morris (1995). Porém, ao analisar individualmente os músculos, é possível observar diferenças significativas $(\mathrm{p}<0,05)$ entre eles.

Músculos como Iliotibialis lateralis apresentam os maiores valores, alcançando em média 6,29. Esse fato caracteriza uma carne próxima ao que chamamos de carne DFD (Dry, Fiber e Dark), uma carne com baixa capacidade de retenção de água e de coloração escura. É possível observar que esse mesmo músculo apresenta o menor valor de luminosidade, o que está de acordo com esse dado, porém esse músculo não apresenta problemas em relação à qualidade do mesmo.

É possível observar ainda, que músculos como o Iliofibularis apresentam os menores valores de $\mathrm{pH}$, e mesmo assim são superiores aos observados em outras espécies. Entre estes dois músculos se encontram os demais avaliados nesse estudo, que 
Tabela 4. Rendimento de subprodutos da carcaça de avestruzes aos 14 meses de idade.

\begin{tabular}{ccccc}
\hline Músculo & Nome comum & Sexo & Carcaça (\%) & $\mathrm{CV}^{*}$ \\
\hline & Filés & Macho & $4,48 \pm 0,77$ & 13,85 \\
& & Fêmea & $4,27 \pm 0,57$ & 14,88 \\
& & Média & $4,34 \pm 0,37$ & 13,66 \\
\hline Pescoço (\%) & Pescoço & Macho & $3,46 \pm 0,43$ & 12,44 \\
& & Fêmea & $3,58 \pm 0,37$ & 10,32 \\
& & Média & $3,52 \pm 0,38$ & 10,89 \\
\hline Asas (\%) & \multirow{2}{*}{ Asas } & Macho & $1,41 \pm 0,10$ & 7,08 \\
& & Fêmea & $1,50 \pm 0,20$ & 13,62 \\
& & Média & $1,45 \pm 0,16$ & 10,94 \\
\hline Fígado (\%) & Fígado & Macho & $1,75 \pm 0,19$ & 8,70 \\
& & Fêmea & $1,29 \pm 0,25$ & 6,42 \\
& & Média & $1,52 \pm 0,23$ & 14,91 \\
\hline Coração (\%) & Coração & Macho & $1,01 \pm 0,26$ & 13,94 \\
& & Fêmea & $0,89 \pm 0,12$ & 18,91 \\
& & Média & $0,92 \pm 0,14$ & 15,81 \\
\hline
\end{tabular}

Médias seguidas de mesma letra maiúscula na linha e médias seguidas de mesma letra minúscula na coluna não diferem entre si pelo Teste de Tukey ( $\mathrm{p}>0,05)$; ${ }^{*}$ coeficiente de variação. se encontram em uma classificação intermediária entre esses valores de $\mathrm{pH}$.

O estresse característico da ave pode ser considerado como a possível causa do esgotamento do glicogênio muscular e, portanto, um alto $\mathrm{pH}$, porém, segundo a literatura, mesmo as modernas técnicas de abate têm mostrado pouco resultado em minimizar essa característica peculiar.

Com relação à coloração dos cortes é possível observar que a carne de avestruz apresenta uma coloração fortemente avermelhada, sendo que alguns autores sugerem que dependendo da alimentação e do procedimento de abate, podem assumir colorações mais arroxeadas. Segundo Sales (1994), isso ocorre devido à mesma possuir altas quantidades de ferro. Ao avaliar a coloração dos músculos em relação ao sexo, observou-se que a luminosidade (valor $\left.{ }^{\star} \mathrm{L}\right)$ foi maior para os machos $(\mathrm{p}<0,05)$, contribuindo significativamente para que a carne fosse mais brilhante que a das fêmeas. Embora quando se avaliou o teor de vermelho (valor ${ }^{\star} a$ ) este tenha sido maior para as fêmeas, ainda que não fosse significativo $(\mathrm{p}>0,05)$. O teor de amarelo (valor $\left.{ }^{\star} b\right)$ foi semelhante $(\mathrm{p}>0,05)$ para ambos os sexos. Não

Tabela 5. Aspectos físicos dos músculos desossados de avestruzes aos 14 meses de idade, por região anatômica.

\begin{tabular}{|c|c|c|c|c|c|}
\hline & Sexo & Músculos da coxa & Músculos da sobrecoxa & Músculos do dorso & Média \\
\hline \multirow[t]{4}{*}{ Temperatura $\left({ }^{\circ} \mathrm{C}\right)$} & Macho & $13,19 \pm 0,88$ & $13,55 \pm 0,69$ & $13,58 \pm 0,86$ & 13,44 \\
\hline & Fêmea & $12,84 \pm 0,38$ & $12,98 \pm 0,25$ & $12,96 \pm 0,43$ & 12,93 \\
\hline & Média & 13,02 & 13,26 & 13,27 & 13,18 \\
\hline & $\mathrm{CV}^{*}$ & 4,54 & 3,56 & 5,77 & 4,79 \\
\hline \multirow[t]{4}{*}{$\mathrm{pH}$} & Macho & $5,92 \pm 0,07$ & $6,02 \pm 0,21$ & $6,10 \pm 0,33$ & 6,01 \\
\hline & Fêmea & $6,20 \pm 0,27$ & $6,23 \pm 0,35$ & $6,21 \pm 0,36$ & 6,28 \\
\hline & Média & 6,06 & 6,18 & 6,20 & 6,15 \\
\hline & $\mathrm{CV}^{*}$ & 4,19 & 5,00 & 4,13 & 4,64 \\
\hline \multirow[t]{4}{*}{ Valor $\mathrm{L}^{*}$} & Macho & $24,75 \pm 4,35$ & $21,48 \pm 5,34$ & $23,03 \pm 6,21$ & $23,09^{a}$ \\
\hline & Fêmea & $20,55 \pm 5,53$ & $17,44 \pm 4,59$ & $16,67 \pm 5,81$ & $18,22^{\mathrm{b}}$ \\
\hline & Média & 22,65 & 19,46 & 19,85 & 20,65 \\
\hline & $\mathrm{CV}^{*}$ & 20,10 & 16,21 & 29,98 & 25,89 \\
\hline \multirow[t]{4}{*}{ Valor $\mathrm{a}^{*}$} & Macho & $24,95 \pm 7,79$ & $26,81 \pm 6,55$ & $26,15 \pm 6,67$ & 25,97 \\
\hline & Fêmea & $26,37 \pm 6,54$ & $25,40 \pm 4,68$ & $29,25 \pm 5,42$ & 27,01 \\
\hline & Média & 25,66 & 26,11 & 27,70 & 26,49 \\
\hline & $\mathrm{CV}^{*}$ & 8,26 & 9,95 & 13,56 & 13,99 \\
\hline \multirow[t]{4}{*}{ Valor $b^{*}$} & Macho & $15,95 \pm 5,25$ & $21,92 \pm 6,88$ & $26,80 \pm 2,31$ & 21,56 \\
\hline & Fêmea & $17,85 \pm 3,68$ & $20,30 \pm 6,75$ & $26,44 \pm 4,35$ & 21,53 \\
\hline & Média & 16,90 & 21,11 & 26,62 & 21,54 \\
\hline & $\mathrm{CV}^{*}$ & 6,54 & 15,94 & 11,75 & 13,85 \\
\hline
\end{tabular}

Médias seguidas de mesma letra maiúscula na linha e médias seguidas de mesma letra minúscula na coluna não diferem entre si pelo Teste de Tukey ( $\mathrm{p}>0,05)$; ${ }^{\star}$ coeficiente de variação.

Tabela 6. Aspectos físicos dos principais músculos de avestruzes aos 14 meses de idade.

\begin{tabular}{lccccc}
\hline \multirow{2}{*}{$\mathrm{CV}^{*}$} & $\mathrm{~T}{ }^{\circ} \mathrm{C}$ & $\mathrm{pH}$ & Valor ${ }^{*} \mathrm{~L}$ & Valor $^{*} \mathrm{a}$ & \multicolumn{2}{c}{ Valor $^{*} \mathrm{~b}$} \\
\cline { 2 - 6 } & 5,44 & 3,59 & 25,81 & 23,19 & 13,32 \\
\hline Gastrocnemius internus & $13,17 \pm 0,3$ & $6,18 \pm 0,3^{\mathrm{AB}}$ & $16,28 \pm 4,4^{\mathrm{B}}$ & $26,65 \pm 5,1$ & $15,87 \pm 3,0^{\mathrm{B}}$ \\
Gastrocnemius externus & $13,12 \pm 0,6$ & $6,08 \pm 0,1^{\mathrm{BC}}$ & $25,93 \pm 5,7^{\mathrm{A}}$ & $22,32 \pm 5,0$ & $15,15 \pm 3,8^{\mathrm{B}}$ \\
Femurotibialis complex & $12,83 \pm 0,6$ & $6,00 \pm 0,2^{\mathrm{BC}}$ & $20,72 \pm 3,8^{\mathrm{AB}}$ & $28,93 \pm 7,1$ & $19,55 \pm 4,6^{\mathrm{B}}$ \\
Iliotibialis lateralis & $13,26 \pm 0,7$ & $6,29 \pm 0,2^{\mathrm{A}}$ & $18,89 \pm 6,8^{\mathrm{B}}$ & $26,35 \pm 6,0$ & $25,55 \pm 3,1^{\mathrm{A}}$ \\
Iliofibularis & $13,20 \pm 0,7$ & $5,97 \pm 0,1^{\mathrm{C}}$ & $23,09 \pm 6,5^{\mathrm{AB}}$ & $28,056 \pm 7,0$ & $29,00 \pm 4,2^{\mathrm{A}}$ \\
Obturatorius medialis & $13,20 \pm 0,7$ & $6,02 \pm 0,2^{\mathrm{BC}}$ & $21,30 \pm 4,5^{\mathrm{AB}}$ & $26,92 \pm 6,3$ & $27,37 \pm 3,2^{\mathrm{A}}$ \\
\hline
\end{tabular}

Médias seguidas de mesma letra maiúscula na linha e médias seguidas de mesma letra minúscula na coluna não diferem entre si pelo Teste de Tukey ( $\mathrm{p}>0,05)$; ${ }^{*}$ coeficiente de variação. 
houve diferença significativa $(p>0,05)$ para nenhum dos matizes (valor ${ }^{\star} \mathrm{L},{ }^{*} \mathrm{a} \mathrm{e}^{\star} \mathrm{b}$ ) entre as diferentes regiões anatômicas avaliadas.

Porém, ao analisar os músculos individualmente, observouse que alguns músculos como o Gastrocnemius internus e o Iliotibialis lateralis apresentaram-se muito mais luminosos que o Gastrocnemius externus, caracterizando-se por um aspecto mais rosado, uma vez que o teor de vermelho não apresentou diferenças significativas $(\mathrm{p}>0,05)$ entre eles.

$\mathrm{O}$ teor de amarelo apresentou diferenças significativas $(p<0,05)$ entre os músculos. Esse fato, em conjunto com as características de luminosidade e teor de vermelho, conferem aos diferentes músculos uma coloração própria.

O grande marketing da carne de avestruz tem ocorrido devido aos seus altos valores nutricionais. Diante disso, as propriedades químicas ou nutricionais observadas neste estudo são apresentadas na Tabela 7.

Em relação às características químicas avaliadas foi possível observar que estas apresentam níveis superiores aos descritos anteriormente por (CARBÓ, 2003; CARRER, 2004; GIANNONI, 1996; SABBIONI, 2003).

Não houve diferença significativa $(p>0,05)$ em relação ao sexo para nenhuma das características avaliadas. Porém, podemse observar essas diferenças entre os diferentes músculos.
A umidade presente nos diferentes músculos apresentou diferenças significativas $(p<0,05)$ entre eles. Músculos como o Gastrocnemius internus apresenta uma maior quantidade de água em seu interior, contribuindo para uma menor perda de água durante cozimentos mais longos, enquanto que o Femurotibialis complex possui menos água, sendo necessário um menor tempo de cozimento para que não ocorra perda de nutrientes. Os demais músculos apresentam valores intermediários entre ambos.

Foi possível observar que há diferenças significativas $(\mathrm{p}<0,05)$ em relação ao teor de proteína nos diferentes músculos. Os músculos Gastrocnemius externus e Femurotibialis complex possuem os teores mais elevados de proteína bruta, enquanto que o Obturatorius medialis possui o menor teor. Sendo que, segundo Sales (1996), essa proteína é rica principalmente em creatina e outros aminoácidos essenciais, tornando-a uma excelente fonte protéica, principalmente para atletas e pessoas com necessidades nutricionais específicas.

Houve diferenças significativas $(\mathrm{p}<0,05)$ em relação aos lipídios presentes nos diferentes músculos avaliados da carcaça de avestruz. Sendo que, músculos como Gastrocnemius internus apresentaram os menores valores, cerca de $1,91 \%$, enquanto que o Obturatorius medialis apresenta em média $3,83 \%$, o que pode ser considerado um ótimo atributo, inclusive em relação às características sensoriais, uma vez que os lipídios são os grandes responsáveis em atribuir sabor e maciez às carnes.

Tabela 7. Propriedades químicas dos principais músculos de avestruzes aos 14 meses de idade.

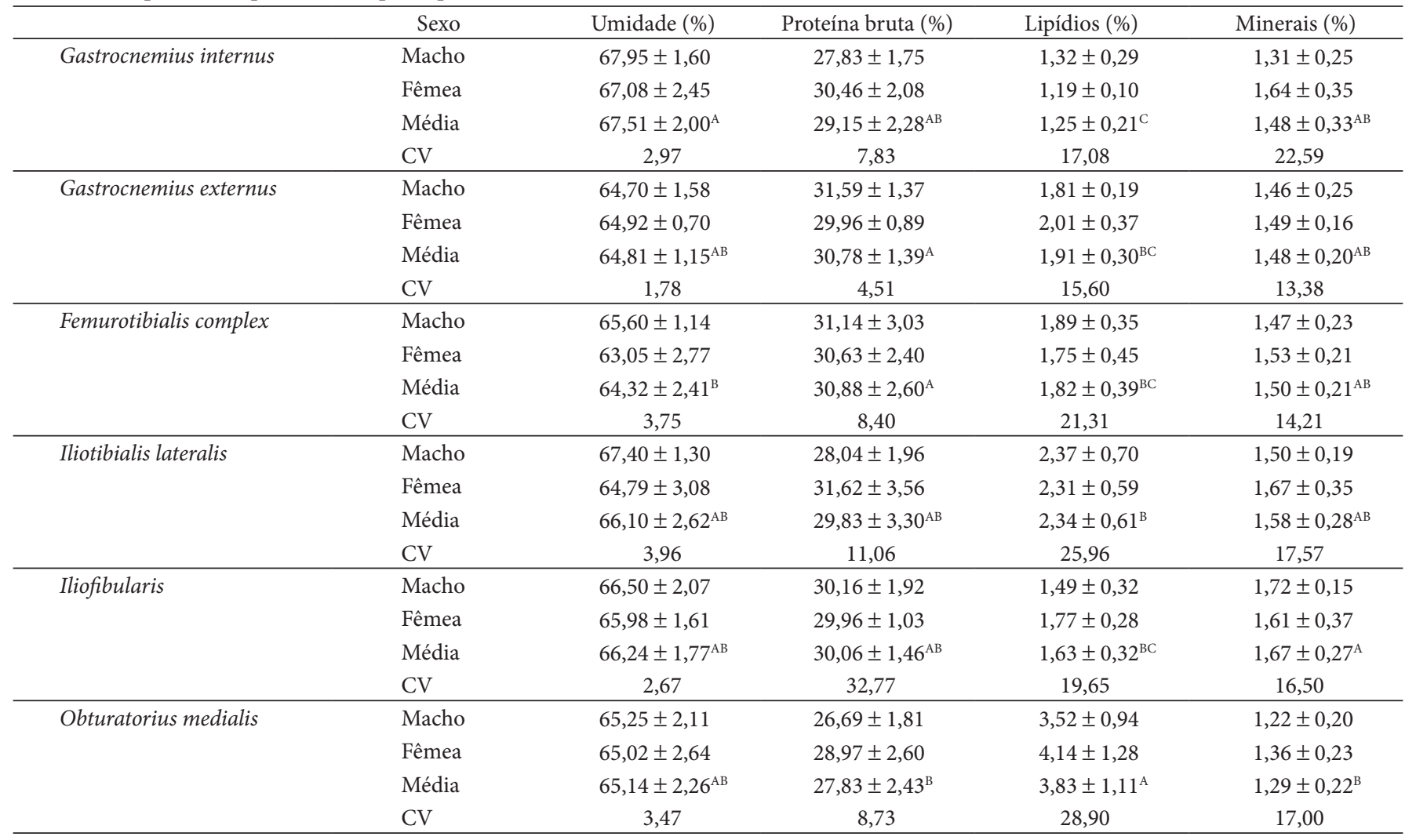

Médias seguidas de mesma letra maiúscula na linha e médias seguidas de mesma letra minúscula na coluna não diferem entre si pelo Teste de Tukey ( $\mathrm{p}>0,05$ ); $\mathrm{e}^{\star}$ coeficiente de variação. 
O teor de minerais presente na carne de avestruz apresentou diferenças significativas $(p<0,05)$ em relação aos diferentes músculos. O músculo mais rico em minerais é o Iliofibularis, com cerca de $1,67 \%$ em relação ao Obturatorius medialis, com 1,29\%. Em média, o valor obtido entre os músculos (1,50 mg.100 g ${ }^{-1}$ de porção comestível) está um pouco acima do citado por Carbó (2003), 1,07 mg.100 g -1 de porção comestível, conferindo um maior valor nutricional, do ponto de vista dos minerais, à carne de avestruz brasileira. Sendo que esse teor é composto principalmente por fósforo, potássio, ferro e zinco.

A composição mineral observada neste estudo está apresentada na Tabela 8 .

O fósforo, bem como o magnésio, o ferro e o manganês presentes nas amostras, não apresentou diferenças significativas $(\mathrm{p}>0,05)$ entre os músculos. O ferro é o mineral mais citado para atrair consumidores quanto à qualidade nutricional da carne de avestruz, pois apresentou valores que realmente comprovam esse marketing. Os teores observados, 12,25 em média, são superiores aos descritos anteriormente. Isso pode ser explicado pelo fato de que a maioria dos autores avaliaram a composição mineral na carne de avestruz na década de 90, quando não eram utilizados programas nutricionais adequados a estes animais, porém hoje a nutrição de avestruzes está muito mais aprimorada, assim como há um melhor material genético utilizado.

O potássio apresentou diferenças significativas $(\mathrm{p}<0,05)$, sendo que os músculos Gastrocnemius internus, Femorotibialis complex, Iliotibialis lateralis e Iliofibularis possuem um maior teor deste mineral em relação ao Obturatorius medialis. E o Gastrocnemius externus não diferiu estatisticamente ( $p>0,05)$ dos demais.

Em relação ao cálcio presente nos músculos, foi possível observar diferenças significativas $(\mathrm{p}<0,05)$ entre estes. Assim como para o zinco, sendo o Femorotibialis complex o músculo que mais apresenta este mineral, seguido pelos músculos da coxa, Gastrocnemius internus e Gastrocnemius externus, e em seguida pelo Iliotibialis lateralis, Iliofibularis e Obturatorius medialis. Mais uma vez observaram-se valores acima dos descritos anteriormente, porém muitos fatores podem estar envolvidos nesta diferença, inclusive a metodologia utilizada para a determinação dos minerais, sendo esta a mais utilizada recentemente.

Os resultados obtidos não apresentaram diferenças significativas ( $p>0,05)$ entre os sexos, por isso os valores não são apresentados na tabela.

\section{Conclusões}

O rendimento das carcaças de avestruzes destinados ao abate comercial no Brasil tem sido satisfatório e comparável à média mundial, o que demonstra o empenho entre os criadores e abatedouros brasileiros em produzir carne de avestruz de maneira competitiva e rentável, porém ainda é necessário que este rendimento seja melhorado, através de melhoramento genético e que haja uma padronização dos cortes para que assim possam competir favoravelmente no âmbito produtivo e zootécnico.

A carne de avestruz apresenta um alto $\mathrm{pH}$ final, fato este que não influenciou negativamente as características físicas e nutricionais, sendo que os níveis de nutrientes e minerais presentes na carne de avestruzes criados no Brasil encontramse acima da média mundial, caracterizando assim uma carne ainda mais saudável.

\section{Referências bibliográficas}

AOAC - Association of Official Analytical. Official method of analysis. 16 ed. Chemists Inc, Arlington, VA, 1997.

ACAB. Anuário da Estrutiocultura Brasileira 2005/06. p. 114-115.

CARBÓ, C. B. Producción del Avestruz: Aspectos claves. 1. ed. Madri: Ed. Mundi-Prensa, 2003. p. 461-472.

CARRER, C. C. A criação do avestruz: guia completo de A a Z. Pirassununga, SP: Ed. Ostrich do Brasil, 2004. p. 192-194.

CARRER, C. C.; KORNFELD, M. E. A criação de avestruzes no Brasil. Pirassununga, São Paulo: Ed. Ostrich do Brasil, 1999.

FLETCHER, D. L.; QIAO, M.; SMITH, D. P. The relationship of raw broiler breast meat color and $\mathrm{pH}$ to cooked meat color and $\mathrm{pH}$. Poultry Science, Stanford, v. 79, p. 784-788, 2000.

Tabela 8. Composição mineral (mg.100 $\mathrm{g}^{-1}$ de porção comestível) dos principais músculos de avestruzes aos 14 meses de idade.

\begin{tabular}{|c|c|c|c|c|c|c|c|c|c|}
\hline & & $\mathrm{P}$ & $\mathrm{K}$ & $\mathrm{Ca}$ & $\mathrm{Mg}$ & $\mathrm{Cu}$ & $\mathrm{Fe}$ & $\mathrm{Mn}$ & $\mathrm{Zn}$ \\
\hline \multirow{2}{*}{$\begin{array}{l}\text { Gastrocnemius } \\
\text { internus }\end{array}$} & Média & $91,60 \pm 3,29$ & $132,00 \pm 4,47^{\mathrm{A}}$ & $5,80 \pm 0,84^{\mathrm{A}}$ & $9,40 \pm 0,55$ & $0,46 \pm 0,05^{\mathrm{B}}$ & $11,64 \pm 1,57$ & $0,10 \pm 0,01$ & $15,64 \pm 2,56^{\mathrm{B}}$ \\
\hline & $\mathrm{CV}^{*}$ & 3,59 & 3,39 & 14,42 & 5,83 & 11,9 & 13,5 & 0,05 & 16,3 \\
\hline \multirow{2}{*}{$\begin{array}{l}\text { Gastrocnemius } \\
\text { externus }\end{array}$} & Média & $89,40 \pm 1,52$ & $122,00 \pm 4,47^{\mathrm{AB}}$ & $5,40 \pm 0,55^{\mathrm{AB}}$ & $10,0 \pm 0,71$ & $0,52 \pm 0,13^{\mathrm{B}}$ & $14,18 \pm 2,29$ & $0,10 \pm 0,01$ & $15,24 \pm 5,30^{\mathrm{B}}$ \\
\hline & $\mathrm{CV}^{*}$ & 1,70 & 3,66 & 10,14 & 7,07 & 25,0 & 16,12 & 0,05 & 34,7 \\
\hline \multirow{2}{*}{$\begin{array}{l}\text { Femurotibialis } \\
\text { complex }\end{array}$} & Média & $92,20 \pm 3,70$ & $126,00 \pm 13,42^{\mathrm{A}}$ & $5,20 \pm 0,45^{\mathrm{AB}}$ & $9,80 \pm 0,45$ & $0,46 \pm 0,05^{\mathrm{B}}$ & $10,66 \pm 1,28$ & $0,10 \pm 0,01$ & $17,84 \pm 2,60^{\mathrm{A}}$ \\
\hline & $\mathrm{CV}^{*}$ & 4,01 & 10,65 & 8,60 & 4,56 & 11,9 & 12,02 & 0,05 & 14,5 \\
\hline \multirow{2}{*}{$\begin{array}{l}\text { Iliotibialis } \\
\text { lateralis }\end{array}$} & Média & $89,20 \pm 4,02$ & $126,00 \pm 8,94^{\mathrm{A}}$ & $5,60 \pm 0,89^{A}$ & $9,80 \pm 0,45$ & $0,48 \pm 0,11^{\mathrm{B}}$ & $11,84 \pm 2,39$ & $0,10 \pm 0,01$ & $11,56 \pm 1,19^{\mathrm{C}}$ \\
\hline & $\mathrm{CV}^{*}$ & 4,51 & 7,10 & 15,97 & 4,56 & 22,8 & 20,18 & 0,05 & 10,3 \\
\hline \multirow[t]{2}{*}{ Iliofibularis } & Média & $89,00 \pm 3,39$ & $130,00 \pm 7,07^{\mathrm{A}}$ & $5,40 \pm 0,55^{\mathrm{AB}}$ & $9,80 \pm 0,45$ & $0,42 \pm 0,04^{\mathrm{B}}$ & $11,96 \pm 3,25$ & $0,10 \pm 0,01$ & $8,24 \pm 1,28^{\mathrm{D}}$ \\
\hline & $\mathrm{CV}^{*}$ & 3,81 & 5,44 & 10,14 & 4,56 & 10,6 & 27,18 & 0,05 & 15,5 \\
\hline \multirow{2}{*}{$\begin{array}{l}\text { Obturatorius } \\
\text { medialis }\end{array}$} & Média & $87,60 \pm 1,82$ & $110,00 \pm 0,01^{\mathrm{B}}$ & $4,20 \pm 0,45^{\mathrm{B}}$ & $9,40 \pm 0,55$ & $0,70 \pm 0,10^{\mathrm{A}}$ & $13,22 \pm 2,59$ & $0,16 \pm 0,13$ & $4,58 \pm 0,83^{\mathrm{E}}$ \\
\hline & $\mathrm{CV}^{*}$ & 2,07 & 0,05 & 10,65 & 5,83 & 14,2 & 19,63 & 50,8 & 18,1 \\
\hline
\end{tabular}

Médias seguidas de mesma letra minúscula na linha e médias seguidas de mesma letra maiúscula na coluna não diferem entre si pelo Teste de Tukey (p >0,05). 
GIANNONI, M. L. Emas \& Avestruzes. Uma alternativa para o produtor rural. Jaboticabal, São Paulo: FUNEP, UNESP, 1996

HOFFMAN, L. C.; MELLET, F. D. Quality characteristics of low fat ostrich meat patties formulated with either pork lard or modified corn starch, soya isolate and water. Meat Science, Londres, v. 65, p. 869-875, 2003.

HORBAÑCZUK, J. et al. Cholesterol content and fatty acid composition of ostrich meat as influenced by subspecies. Meat Science, Londres, v. 50, p. 385-388, 1998.

KNOWLES, T. G. A review of the road transport of cattle. Veterinary Record, London, v. 144, n. 8, p. 197-201, 1999.

LIMA, D. L. Abate Humanitário de Avestruz e Rendimento de Carcaça, AmericAvestruz, 2005, Salvador - BA. Anais... Salvador/ BA, 2005.

MALAVOLTA, E.; VITTI, G. C.; OLIVEIRA, S. A. de. Avaliação do estado nutricional das plantas: princípios e aplicações. 2. ed. Piracicaba: POTAFOS, 1997, p. 319.

MORRIS C. A. Ostrich slaughter and fabrication: 1. Slaughter yields of carcasses and effects of electrical stimulation on post mortem ph. Poultry Science, Stanford, v. 74, n. 1, p. 1683-1687, 1995.

MUNIZ, L. R. Perpectivas da Carne de Avestruz: Criação, Industrialização e Mercado Consumidor. São Paulo, 2004.

PARDI, M. C. Ciência, higiene e tecnologia da carne. Goiânia: Ed. Da UFG, 2001.
POLLOK, K. D. The nutritional profile of cooked and raw ostrich meat. Ranger: Amercian Ostrich, 1997. p. 39-45.

SABBIONI, A. Factors affecting ostrich meat composition and quality. Annimale Facoltá di Medicina Veterinaria di Parma, Parma, v. 23, n. 1, p. 243-252, 2003.

SALES, J. Histological, biophysical, physical and chemical characteristics of different ostrich muscles. Journal of Science and Food Agriculture, London, v. 70, p. 109-114, 1996.

SALES, J. Identification and improvement of quality characteristics of ostrich meat. Stellenbosch, 1994. Tese (Pós-Doutorado), University of Stellenbosch.

SALES, J.; MELLETT, F. D. Post-mortem ph decline in different ostrich muscles. Meat Science, London, v. 34, p. 401-410, 1995.

SAS/STAT. User's Guide (release 6.03 ed). Cary, NC, SAS Institute, 1999.

SEGÒVIA, M. B.; MUNIZ, L. R. Estudo do Rendimento Percentual da Carcaça Desossada do "Struthio camelus". Anuário 2004 do SCVCF, São Paulo, v. 5, n. 1, p. 116-122, 2004.

SWART, D. The evaluation of the economic value of the skin, meat and feathers on the live ostrich. Department of Agriculture Report. Oudtshoorn Experimental Station, South Africa, 1981.

WARRIS, P. D. The handling of cattle pre-slaughter and its effects on carcass meat quality. Applied Animal Behaviour Science, Amsterdan, v. 28, p. 171-186, 1990. 